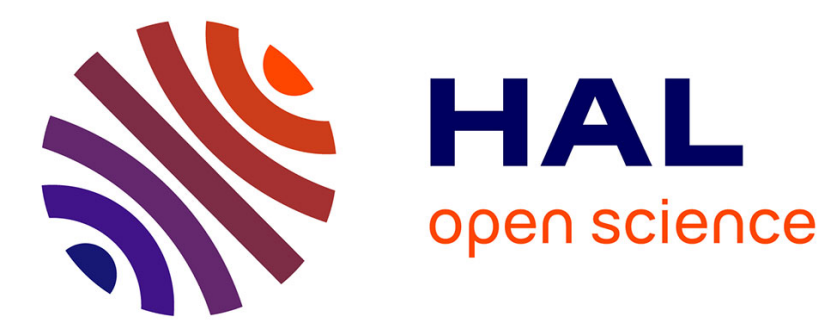

\title{
Phenomenological modeling of abradable wear in turbomachines
}

Bérenger Berthoul, Alain Batailly, Laurent Stainier, Mathias Legrand, Patrice Cartraud

\section{- To cite this version:}

Bérenger Berthoul, Alain Batailly, Laurent Stainier, Mathias Legrand, Patrice Cartraud. Phenomenological modeling of abradable wear in turbomachines. Mechanical Systems and Signal Processing, 2018, 98, pp.770-785. 10.1016/j.ymssp.2017.05.020 . hal-01569316

\section{HAL Id: hal-01569316 https://hal.science/hal-01569316}

Submitted on 26 Jul 2017

HAL is a multi-disciplinary open access archive for the deposit and dissemination of scientific research documents, whether they are published or not. The documents may come from teaching and research institutions in France or abroad, or from public or private research centers.
L'archive ouverte pluridisciplinaire HAL, est destinée au dépôt et à la diffusion de documents scientifiques de niveau recherche, publiés ou non, émanant des établissements d'enseignement et de recherche français ou étrangers, des laboratoires publics ou privés. 


\title{
Phenomenological modeling of abradable wear in turbomachines
}

\author{
Bérenger Berthoul $^{\mathrm{a}}$, Alain Bataillyc ${ }^{\mathrm{c}}$, Laurent Stainier ${ }^{\mathrm{a}}$, Mathias Legrand ${ }^{\mathrm{b}}$, \\ Patrice Cartraud ${ }^{\mathrm{a}}$ \\ ${ }^{a}$ Institut de recherche en Génie Civil et Mécanique, UMR 6183 CNRS-ECN-UN, Ecole Centrale de Nantes, 1 rue de la \\ Noë, BP 92101, 44321 Nantes, France \\ ${ }^{b}$ Structural Dynamics and Vibration Laboratory, McGill University, 817 Sherbrooke West, H3A-0C3, Montréal, Québec, \\ Canada \\ ${ }^{c}$ Département de génie mécanique, École Polytechnique de Montréal, H3C 3A7, Montréal, Québec, Canada
}

\begin{abstract}
Abradable materials are widely used as coatings within compressor and turbine stages of modern aircraft engines in order to reduce operating blade-tip/casing clearances and thus maximize energy efficiency. However, rubbing occurrences between blade tips and coating liners may lead to high blade vibratory levels and endanger their structural integrity through fatigue mechanisms. Accordingly, there is a need for a better comprehension of the physical phenomena at play and for an accurate modeling of the interaction, in order to predict potentially unsafe events. To this end, this work introduces a phenomenological model of the abradable coating removal based on phenomena reported in the literature and accounting for key frictional and wear mechanisms including plasticity at junctions, ploughing, micro-rupture and machining. It is implemented within an in-house software solution dedicated to the prediction of full three-dimensional blade/abradable coating interactions within an aircraft engine low pressure compressor. Two case studies are considered. The first one compares the results of an experimental abradable test rig and its simulation. The second one deals with the simulation of interactions in a complete low-pressure compressor. The consistency of the model with experimental observations is underlined, and the impact of material parameter variations on the interaction and wear behavior of the blade is discussed. It is found that even though wear patterns are remarkably robust, results are significantly influenced by abradable coating material properties.
\end{abstract}

Keywords: rotor/stator interaction; rubbing; nonlinear dynamics; contact dynamics; friction; abradable coating; wear of materials

\section{Introduction}

Abradable coatings have long been used by aircraft engine manufacturers as sacrificial materials in order to reduce operating clearances between the bladed disk and the casing in both compressor and turbine stages. These coatings advantageously mitigate potential parasitic leakage flows from a stage to the next one by geometrically adapting their profile in case of contacts with a blade thus preventing potentially hazardous structural damages [19]. The nature of the coating and its mechanical properties are adjusted depending on where it is implemented in the engine: as an example, a coating sprayed on the casing of a low-pressure compressor does not require the same thermal resistance as its counterpart sprayed in the high-pressure turbine. Accordingly, a wide variety of abradable coatings such as ceramics, aluminum/silicon alloys or nickel/graphite composites to name a few [26] might be employed. These materials may be sprayed, sintered or even deposited with a honeycomb structure on the casing [26]. As a direct consequence, during blade-tip/abradable coating unilateral contact occurrences, distinct physical mechanisms may be at play. Understanding these mechanisms is important because while an isolated blade/abradable contact does not threaten the blade integrity by itself, repeated contacts could lead to unwanted vibratory resonances of the blade [19]. Hence the need for a better understanding of the interaction [20] both through experiments and numerical simulations able to predict the interaction for different blade geometries, blade-casing configurations and abradable material behaviors. Several investigations on the static characterization of abradable coatings $[23,11]$ as well as abradability 
investigations carried out statically, or at very low speed, are available [31,32] in addition to a few scratch tests $[15,16]$. Recently, experimental investigations on the dynamic characterization of abradable coatings within a simulated turbo-machinery environment were reported with respect to: a high relative interaction speed (from $100 \mathrm{~m} / \mathrm{s}$ to $500 \mathrm{~m} / \mathrm{s}$ ) [5, 28], elevated temperatures (up to $600^{\circ} \mathrm{C}$ ) [6] as well as a combination of high interaction speeds and elevated temperatures [17, 22]. While the influence of thermal conditions has long been explored [21], experimental works carried out by manufacturers are rarely published.

Concerning the numerical aspects, various blade/casing interaction models were developed over the recent years. Analytical models with simplified contact and no wear $[27,14]$ as well as more sophisticated Finite Element simulations able to accurately reflect the blade geometry and model the abradable coating removal [19] were developed. The main restrictions are the modeling of abradable wear and the computational cost of the overall simulation, hence limited to a few blade revolutions. Very few quantitative models of abradable wear exist in the literature to overcome these problems. A phenomenological model was proposed by Marscher [18], based on observations that were not confirmed in latter experiments. A few qualitative models of abradable wear based on experimental observations were proposed by Schmid [26]. A Finite Element micro model of the bulk material without contact was proposed in [8]. Finally, two abradable coating models in the context of full three-dimensional simulations were suggested with a focus on the numerical efficiency rather than on the physical relevance of wear phenomena [12, 29].

A crucial ingredient for the quantitative study of the blade displacement is to accurately capture the interaction behavior between the tip of the blade and the coating. In this context, a simplified macro-scale model of the interaction is presented in this paper, based on the phenomenology and physics of abradable wear. A model depending only upon experimentally measurable material quantities is targeted. It has been implemented in the numerical framework introduced in [2]. First a synthesis of abradable phenomenology is presented, then a blade/coating interaction model is proposed from the resulting classification. Two studies are then explained: (1) the simulation of an experimental test rig with a fixed blade and a rotating cylinder coated with abradable material [17] and (2) the interaction of a blade with the casing and its abradable coating in a real aircraft engine low pressure compressor.

For the sake of brevity, several key notions related to the analysis of rotor/stator interactions are not recalled in this article. An in-depth literature review about these notions may be found in [10].

\section{Phenomenology of abradable wear}

\subsection{Interaction parameters}

With respect to contact dynamics, blade/coating interactions depend on three main parameters [26]: tangential velocity at the blade tip, temperature and incursion.

In this contribution, attention is paid to blade/coating interactions in aircraft engine low-pressure compressors where typical velocities at the blade tip range from $100 \mathrm{~m} / \mathrm{s}$ to $600 \mathrm{~m} / \mathrm{s}$. Most experiments stand within this range or slower $[1,5,17,28]$. Temperature varies from $0{ }^{\circ} \mathrm{C}$ to $600{ }^{\circ} \mathrm{C}$.

Contrary to tangential velocity and temperature, the incursion, also called bite-per-blade in the literature, cannot be measured precisely during the experimental simulation of an aircraft engine interaction. It may only be estimated from the final wear profile and the number of blade revolutions. Schmid [26] considers various cases with nominal incursions ranging approximately from $0.001 \mu \mathrm{m}$ to $20 \mu \mathrm{m}$. Other experiments $[1,5,17,28]$ operate on ranges from $10 \mu \mathrm{m}$ to $100 \mu \mathrm{m}$. Note that in a vast majority of cases, rotating test rig experiments typically control the bite-per-blade only through the incursion velocity $[26,3]$. Nevertheless, from the material standpoint, the incursion velocity is completely negligible and only the bite-per-blade is of physical significance (as noted, for example, by Schmid [26]).

Because there are several abradable materials and because the three aforementioned parameters (tangential velocity, temperature and bite-per-blade) imply different contact configurations between the blade and the coating, many different observations have been reported in the literature. In the following, a synthesis of these observations is carried out. 


\subsection{Phenomenology}

The behavior of the abradable is quasi-brittle in traction and elastoplastic in compression. Fracture becomes more ductile with temperature [17]. Interaction with gas flux particles goes beyond the scope of the present paper, and is anyway seldom mentioned in the corresponding literature. The main area of interest regarding blade/coating interaction is the coating surface behavior, i.e. friction and wear. Interaction mechanisms are defined by a combination of a distinctive kinematics and a thermodynamic force associated to it. The work exerted between two equilibrium states on an arbitrary abradable system can thus be computed as the sum of all independent mechanism works:

$$
W=\sum_{i} W_{i}
$$

where $W_{i}$ is the work of mechanism $i$ during the interaction. Interaction phenomena reported in the literature are summarized in wear mechanisms described below and listed in Table 1.

\section{Elastodynamics and bulk inelasticity}

Phenomenon There is a deformation of the casing upon the impact of the blade. If the incursion or the temperature is too high, the microstructure of the coating is crushed to depth.

Interpretation The deformation of the coating can be explained by its elastic and plastic properties. Crushing is made possible because of the porosities in the microstructure.

\section{Machining}

Phenomenon The machining mechanism is described in [17]. A continuous abradable chip similar to machining is produced for relatively high temperatures (from $150{ }^{\circ} \mathrm{C}$ to $300{ }^{\circ} \mathrm{C}$ ) and high incursions of the order of $50 \mu \mathrm{m}$.

Interpretation The abradable chip exhibit a "deck of card" morphology, see Fig. 3. It is assumed that this morphology is produced by the coating being sheared by the blade. Shearing of the abradable material is related to its plastic behavior. Highly localized shear strains might be induced by an adiabatic shear band mechanism [30]: high blade velocity prevents deformation from propagating for elastic accommodation. As a consequence, major plastic deformations arise locally. The plastic work done is mainly dissipated as heat which does not have time to diffuse, hence the name adiabatic. The material is softened on a narrow band where it can be sheared easily.

\section{Plasticity at junctions}

Phenomenon The cutting mechanism is described by Borel et al. [3] and then Schmid [26] for incursions below $5 \mu \mathrm{m}$. It is described as a clean cut removal of material: at the scale of the coating or even at the scale of the abradable material micro-structure, no deformation is observed.

Interpretation Since incursions mostly have the same order of magnitude as the rugosity of the abradable coating [26], the cutting process should be viewed as an ever-fluctuating configuration between the blade and the abradable surface. The observation of no deformation in the coating can be explained by the formation of very localized adiabatic shear bands on small protrusions of the coating surface under the blade.

Our interpretation of cutting is very similar to the phenomenon named plasticity at junctions by Rabinowicz [24], resulting in the so-called friction and adhesive wear mechanisms. Plasticity at junctions is the fact that two surfaces in contact over a continuous area are in fact, at the micro-scale, in contact through a much smaller area consisting of small junctions between both surfaces. At this scale, plastic behavior is almost always the main mechanism [24]. The friction force can then be directly associated to the flow stress in shear at junctions; the adhesive wear is explained by the fact that shear may not emerge right at the junction, but inside one of the materials (usually the weakest one, i.e. the abradable in our case). Sometimes however, because of high external temperatures or high energy dissipations, the temperature at the interface is such that the material becomes extremely ductile: it is then sheared inside an area localized at the surface but within the whole junction and not only on a thin shear band (see post-mortem observations in [17]). 


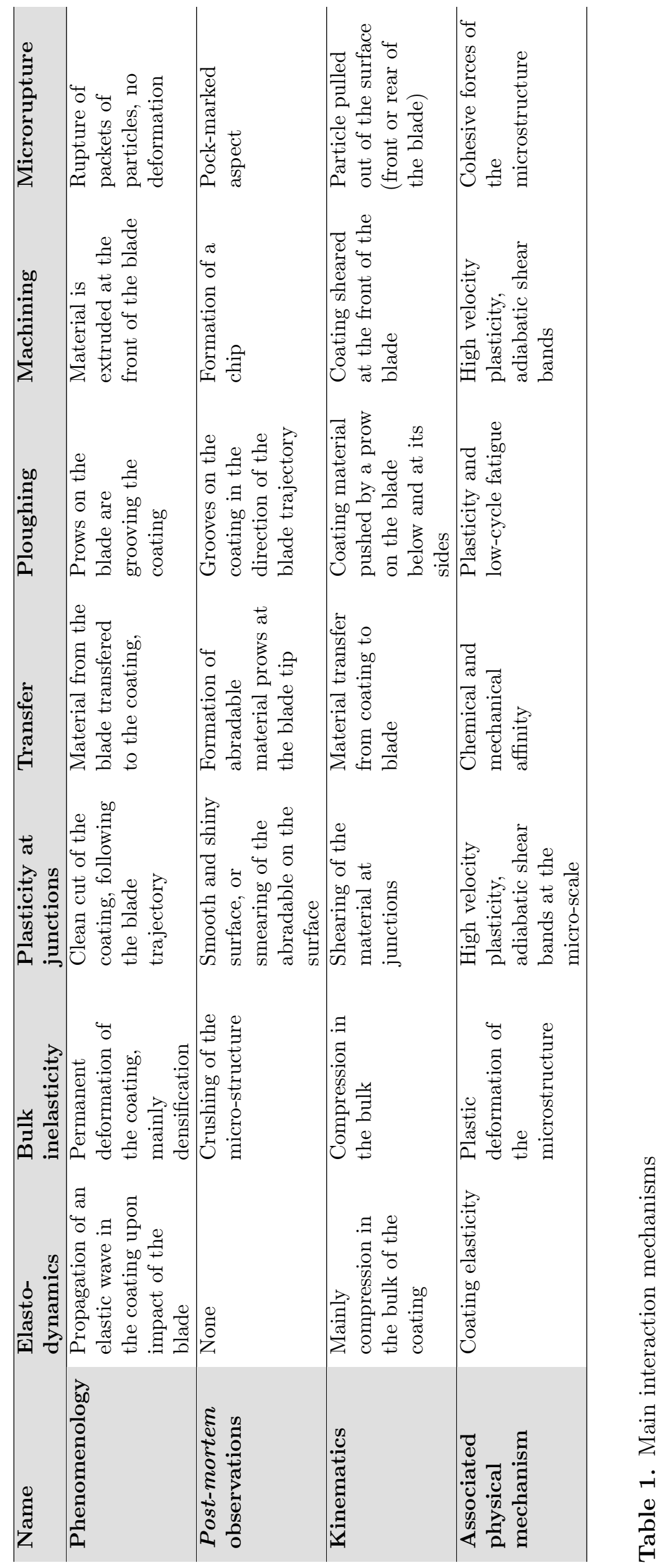


Even if the two mechanisms are caused by plastic shearing, note that machining significantly differs from plasticity at junctions: while machining operates in front of the blade, with a well-defined macro-scale configuration, plasticity at junctions is a mechanism which proceed under the blade with a continuously changing configuration. The two distinct contact geometries can be clearly seen in Fig. 1: with only an average incursion of $5 \mu \mathrm{m}$ at the macro scale, at the micro scale the real incursion is continuously evolving due to the rugosity, and the coating is more likely to be compressed by the blade than sheared in front of it. In contrast, for a $50 \mu \mathrm{m}$ incursion, the coating is likely to be sheared at the front of the blade. Please note that the sole purpose of Fig. 1 is to illustrate different abradable removal configurations. It does not actually represent the geometry of our numerical model (which is done in Fig. 2).

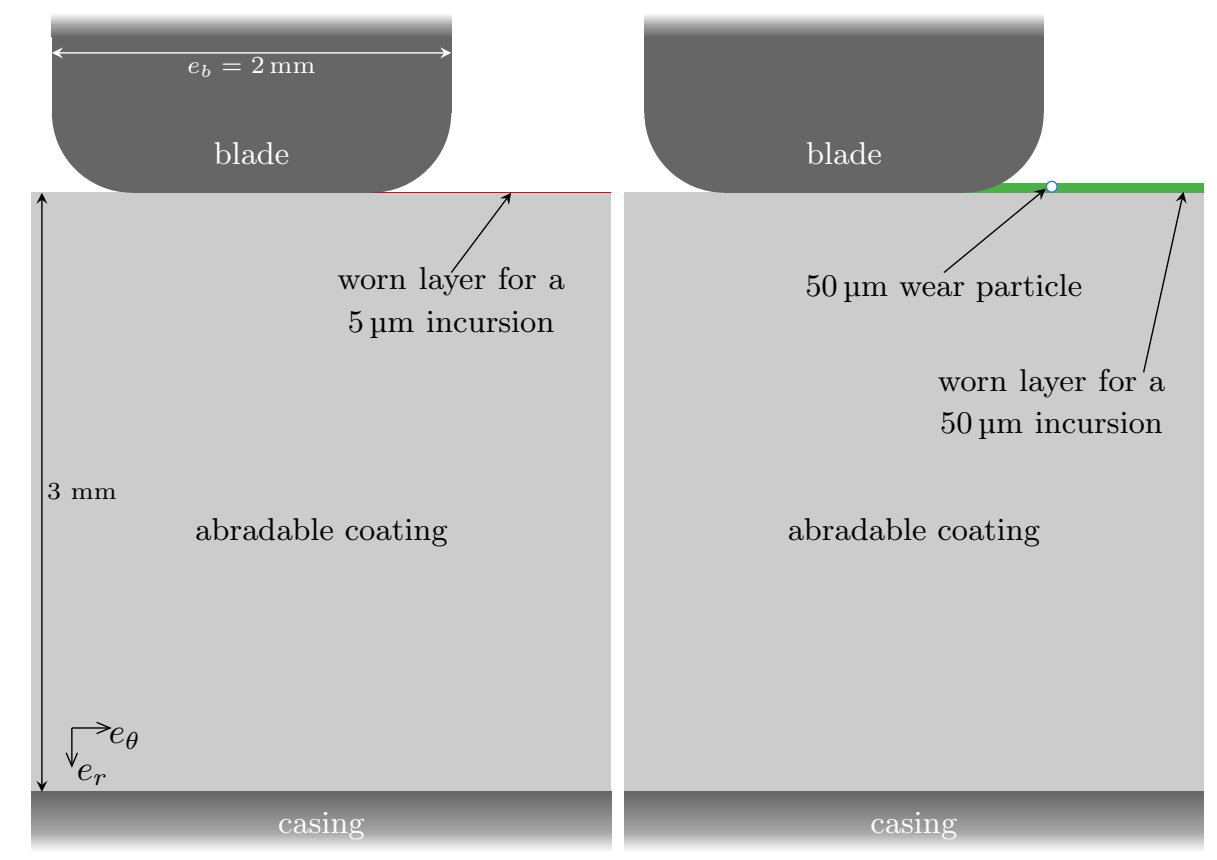

Figure 1. Schematic representation of coating removal with two incursions: $5 \mu \mathrm{m}$ (left) and $50 \mu \mathrm{m}$ (right). Proportions are respected.

\section{Transfer}

Phenomenon Transfer of abradable material to the tip occurs when particles detached from the coating adhere to the blade. They might not remain attached the blade tip: since the bond with the blade tip is weak, they are either ejected when the temperature goes back to normal after a contact peak, or worn out and ejected during another interaction. Sometimes however, particles adhering to the blade tip do build up at each interaction, forming small prows on the blade giving it a saw-tooth profile. Blade tip material may also transfer to the coating [7].

Interpretation The most predominant case is coating-to-blade transfer. Transfer is a side-effect related to adhesive wear: abradable particles detached by adhesive wear sometimes adhere to the blade tip surface. Sometimes abradable particles keep adhering to the tip aggregate in small prows of abradable material that give a saw-tooth profile to the tip. The importance of transfer depends on the temperature during the interaction as well as micro-scale considerations, such as oxidation of the surface, rugosity... In low-pressure compressors, blade-to-coating transfer is rare since the abradable material is much softer than the blade material. However, under heavy rubbing, the blade tip is molten by high temperature and is eventually transferred as a thin layer to the coating.

\section{Ploughing}

Phenomenon Prows on the blade tip are ploughing the abradable material, leaving wear grooves on the coating. 
Interpretation Prows are caused by the transfer mechanism. Interpretation of ploughing is straightforward: there is a lateral plastic flow under the displacement imposed by the prows penetrating the coating. Grooving can be assimilated to the classical wear mechanism known as abrasive wear.

\section{Micro-rupture}

Phenomenon Packets of spray particles are pulled out of the surface by the blade, leaving a pockmarked abradable coating.

Interpretation This mechanism is associated to the fracture properties of the material. Abradable materials are quasi-brittle (at least in traction and at room temperature). Hence, when hit by the blade, the coating can initiate and propagate cracks. Since the incursion is limited to a few micrometers, cracks will propagate at the surface of the coating and detach small amounts of abradable material.

\section{Modeling}

\subsection{General framework}

A drawing of our numerical model is represented in Fig. 2. Because our numerical framework has

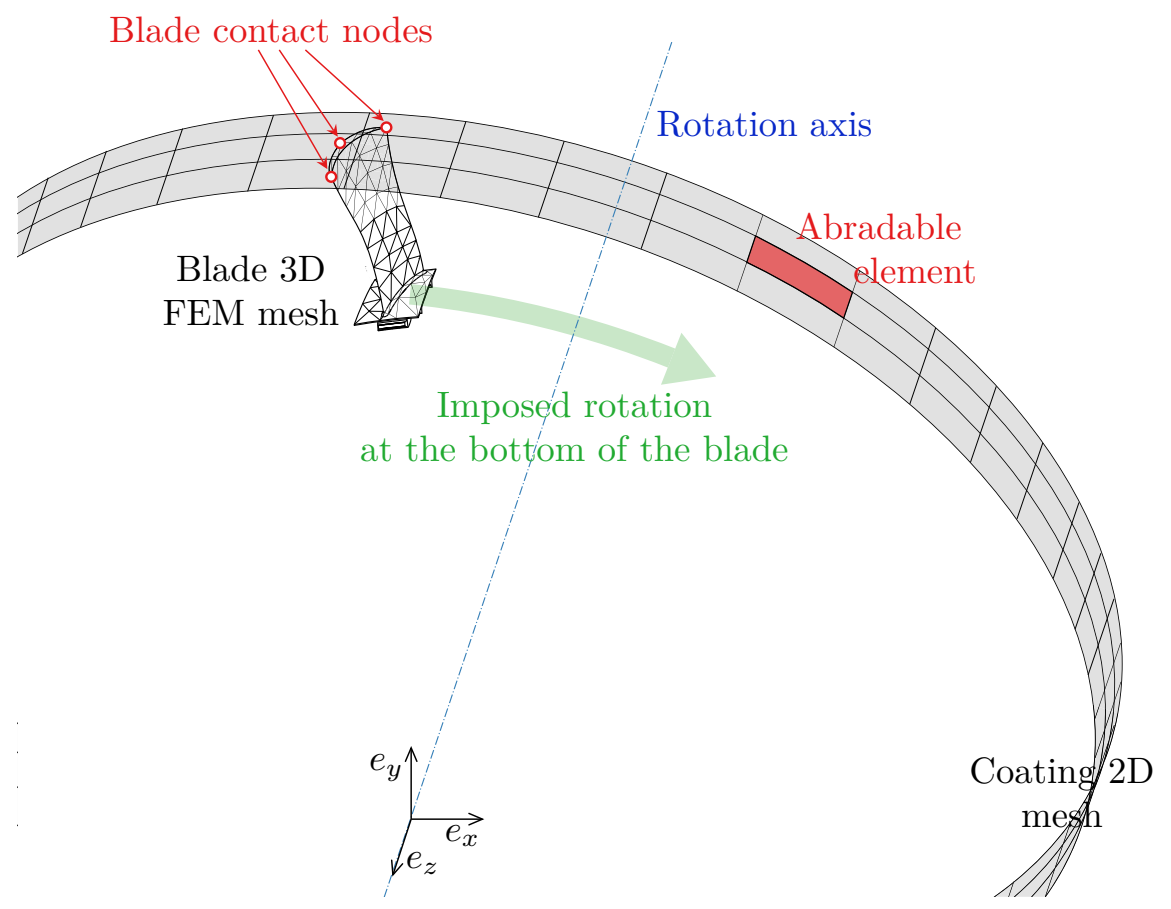

Figure 2. Representation of the numerical simulation between a blade and a coated casing

already been presented extensively [2, 13], only its main characteristics are recalled here: the blade geometry is meshed in 3D and associated finite element matrices are calculated. They are then reduced through a Craig-Bampton [4] component mode synthesis procedure, in order to control the number of degrees of freedom while efficiently handling contact at the blade tip. Centrifugal hardening is taken into account. Then the blade/coating interaction formulation is numerically solved with an explicit time integration scheme.

The abradable coating is represented by a regular quadrangle mesh. Every element is independent and embeds both a volumetric behavior law and surface friction/wear law. The two laws allow to compute the coating reaction to a solicitation of the blade by a direct function evaluation. The interface between the coating reaction and the rest of the simulation is presented in Table 2 .

At each time step, the contact is handled through a prediction-correction procedure: the blade displacement is predicted and the facing abradable element is identified. When a penetration is detected, the force $F_{t}$ exerted by the abradable on the blade (computed based on the formula of the section 
below) is used for the correction of the blade displacement. Wear of the abradable element is also computed for updating the coating topology.

\begin{tabular}{ll}
\hline inputs & $\begin{array}{l}\text { penetration of the blade into the abradable } \\
\text { blade edge velocity }\end{array}$ \\
\hline outputs & contact forces exerted onto the blade \\
& updated abradable surface geometry \\
\hline
\end{tabular}

Table 2. Inputs and outputs of the model

\subsection{Selection of a modeling scale}

The global time-stepping procedure only provides macroscopic quantities from the abradable mesh. Hence two types of modeling of the abradable material are conceivable:

- Ideally, since wear phenomena is one scale lower than the simulation scale, the abradable material should be modeled by deformation and temperature microscopic fields, and then averaged for interaction with the rest of the simulation. This could be achieved by a 3D fine representation of the abradable. However, such a simulation would require the modeling of various difficult problems, such as large deformations, contact, non linear behavior, ductile fracture. To the authors' knowledge, no such simulation has been carried out in the literature, and eventually the associated computational effort would be prohibitive and not affordable in a full blade/casing interaction since it should be integrated at the macro scale of the blade, and during the entire interaction.

- Wear computation can be done directly with macroscopic quantities. This is justified by the fact that during a blade/casing interaction, the blade amplitudes of vibration do not seem to depend on micro scale quantities [19] (such as the precise topology of the surface of the abradable at the scale of the rugosity), but mostly depend on their macroscopic average (the topology at the scale of the blade edge).

Hence the second strategy is selected in this paper. A macroscopic surface behavior modeling, accounting for machining, plasticity at junctions, ploughing and micro-rupture is presented below.

\subsection{Derivation of friction and wear laws}

Note Formula in the following paragraphs are given in the plane orthogonal to the axis of rotation and quantities such as forces are hence given by unit length. The term normal refers to vectors along $\boldsymbol{e}_{r}$, and tangential refers to vectors along $\boldsymbol{e}_{\theta}$ (cf. Fig. 1).

\subsubsection{Machining}

The simple deck of card model [9] — the continuous chip in experiments is visually close to a deck of card morphology - is used, see Fig. 3. The force induced on the blade by the machining process is defined as:

$$
F^{\mathrm{ma}}=\tau_{y} \frac{\cos \phi}{\sin \phi} \Delta h^{\mathrm{ma}}
$$

where $\tau_{y}$ is the elastic limit in shear. For the wear of a clean cut, the formula reduces to:

$$
\Delta h^{\mathrm{ma}}=I-I_{\mathrm{e}}
$$

where $I$ is the incursion of the blade into the coating, $I_{\mathrm{e}}$, the elastic accommodation of the coating, is defined by $I_{\mathrm{e}}=\sigma_{y} e_{\mathrm{a}} / E_{\mathrm{a}}, E_{\mathrm{a}}$ being the abradable Young Modulus and $e_{\mathrm{a}}$, the thickness of the coating. The shear band angle $\phi$ may depend on the blade geometry, temperature and interaction velocity. 


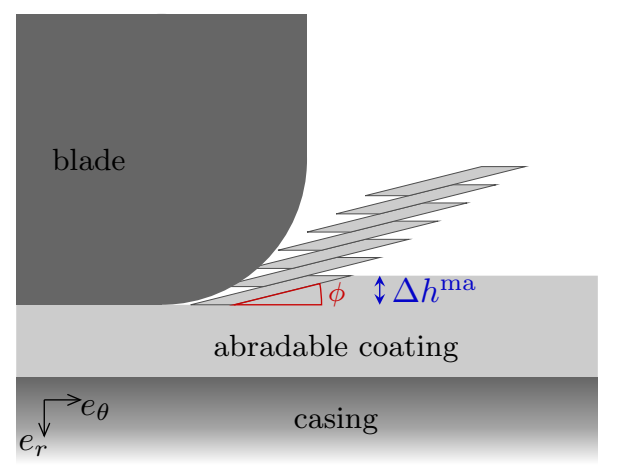

Figure 3. Machining deck of card model. Material is removed by successive shear bands.

\subsubsection{Plasticity at junctions}

Following common practice, Coulomb's friction and Archard's law will be used as they have proven to be relevant with a reduced number of parameters. They have the respective following form:

$$
\begin{aligned}
& F^{\mathrm{adh}}=\mu F_{n} \\
& \Delta h^{\mathrm{adh}}=k^{\mathrm{adh}} e_{\mathrm{b}} \frac{\sigma_{n}}{p}
\end{aligned}
$$

where $k^{\text {adh }}$ is the Archard wear coefficient, $e_{\mathrm{b}}$ the thickness of the blade (see Fig. 1), $\sigma_{n}$ is the pressure at the interface computed from bulk elastic behavior, and $p$ stands for the hardness of the abradable material.

\subsubsection{Ploughing}

Wear induced by ploughing, called abrasive wear in the literature [24], can be modeled by an Archard's type of law:

$$
\Delta h^{\mathrm{ab}}=k^{\mathrm{ab}} e_{\mathrm{b}} \frac{\sigma_{n}}{p}
$$

Regarding the force exerted on the blade, the following relation holds:

$$
F^{\mathrm{ab}}=F^{\mathrm{pp}} n_{\mathrm{pa}}
$$

where the number of particles along the blade edge $n_{\mathrm{pa}}$ can be estimated by looking at the number of grooves on a post-mortem abradable specimen (e.g. in the experiment reported in [17], the abradable layer exihibits a dozen of grooves and the impacting blade is one centimer wide), and $F^{\mathrm{pp}}$, the ploughing force of one particle, can be estimated by scratch tests (e.g. in the experiment reported in [16], the measured force ranges from $40 \mathrm{~N}$ to $140 \mathrm{~N}$ depending on the abradable material).

\subsubsection{Micro-rupture}

Assuming the simplified geometry depicted in Fig. 4, a statistical argument on the energy dissipated when creating detached particles by brittle fracture yields:

$$
F^{\mathrm{mr}}=k^{\mathrm{mr}} \gamma
$$

where $k^{\mathrm{mr}}$ is a factor depending on the form of the particle and $\gamma$ is the cohesive energy of the abradable material. If the particle is a shell covering the coating before being detached, $k^{\mathrm{mr}}=2$. If it is a cube, then $k^{\mathrm{mr}}=6$. From Fig. 4 , the worn thickness is equal to the size of the particle $l_{\text {pa }}$ in the normal direction:

$$
\Delta h^{\mathrm{mr}}=l_{\mathrm{pa}}
$$




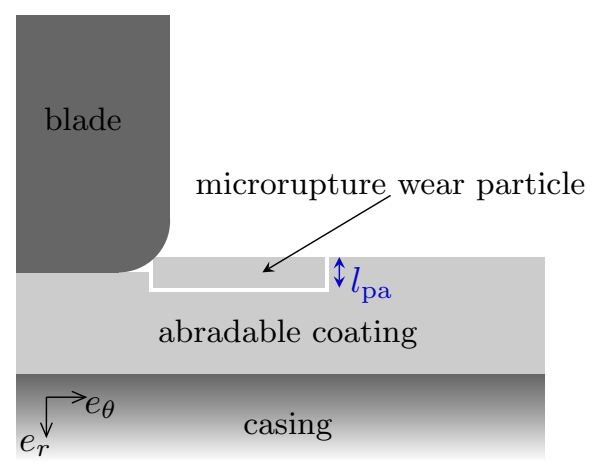

Figure 4. Micro-rupture wear. A particle is formed when the blade impacts the coating.

\subsection{Synthesis}

The presented wear mechanisms shall combine at all times during an interaction. Since they all modify the interaction configuration, the change of coating topology due to one mechanism may affect the others. The influence of each mechanism regarding the whole interaction process is taken into account with a few assumptions. First, it is assumed that friction/adhesive wear and abrasive wear are always active when contact between the blade and the coating is active, and mutually independent, that is, the wear generated by one mechanism is neglected when computing the wear of the other mechanism. This is true as long as their wear is either negligible compared to the incursion, or if the wear is only effective after the interaction (i.e. wear material ejected after, not during, the interaction). Further, micro-rupture and machining are assumed to arise for an elementary surface with respective proportions $p^{\mathrm{mr}}$ and $p^{\mathrm{ma}}$ satisfying $0 \leq p^{\mathrm{mr}}+p^{\mathrm{ma}} \leq 1$ : a zero proportion means that the mechanism is inactive while a unity proportion says that the mechanism takes place over the whole surface described by the blade tip trajectory. These proportions are dependent on the interaction velocity, incursion and temperature. This allows for a representation in the form of wear maps [26]. A precise measurement of $p^{\mathrm{mr}}$ and $p^{\mathrm{ma}}$ is complicated, however an educated guess can be made based on the observations of the literature regarding the appearance of worn surfaces and chips [17][26]. The values used for the numerical studies presented herein have are given in Table 3.

One should also note that the kinematics of the detached material is of importance: Schmid [26] noted that for velocity interactions greater than $100 \mathrm{~m} / \mathrm{s}$, most of the detached material is released as particles at the rear of the blade. In a supplementary experiment at high temperature $300{ }^{\circ} \mathrm{C}$ and high incursions of the blade in the coating $50 \mu \mathrm{m}$ [1], a continuous chip at the front of the blade was forming. In yet another experiment, also at high incursions but at room temperature, particles were released at the front of the machining tool [5]. Also, some mechanisms occur at the front of the blade (micro-rupture and machining) with particles being released either at the front or at the rear, while other emerge under the blade (friction/adhesive wear and abrasive wear). All in all, the scenario of interaction should be:

1. compute the forces due to micro-rupture and machining together,

2. update the topology of the abradable taking into account material ejected at the front of the blade,

3. compute the forces due to friction/adhesive wear and abrasive wear,

4. update the topology again. With simplified notation such as $\Delta h^{\text {adh }}=\Delta h^{\text {adh }}\left(\Delta h^{\mathrm{mr}}, \Delta h^{\mathrm{ma}}\right)$, the formula of abradable wear at the end of the interaction is thus:

$$
\Delta h=\Delta h^{\mathrm{adh}}+\Delta h^{\mathrm{ab}}+p^{\mathrm{mr}} \Delta h^{\mathrm{mr}}+p^{\mathrm{ma}} \Delta h^{\mathrm{ma}}
$$

Since all the mechanisms in this model are supposed to be caused by independent physical phenomena, the total energy given by the blade is the sum of the energies of each mechanism considered independently (the kinetic energy of the detached particles is neglected). This decomposition is also true for forces, hence:

$$
F=F^{\mathrm{fr}}+F^{\mathrm{ab}}+p^{\mathrm{mr}} F^{\mathrm{mr}}+p^{\mathrm{ma}} F^{\mathrm{ma}}
$$




\section{Modeling of an experimental test rig}

\subsection{Test rig presentation}

As a first step to understand the behavior of wear models coupled with the numerical time-integration strategy described above, an attempt is made to reproduce the experimental configuration presented in [1]. A diagram of the test rig is given in Fig. 5. A cylinder is coated with abradable material. The

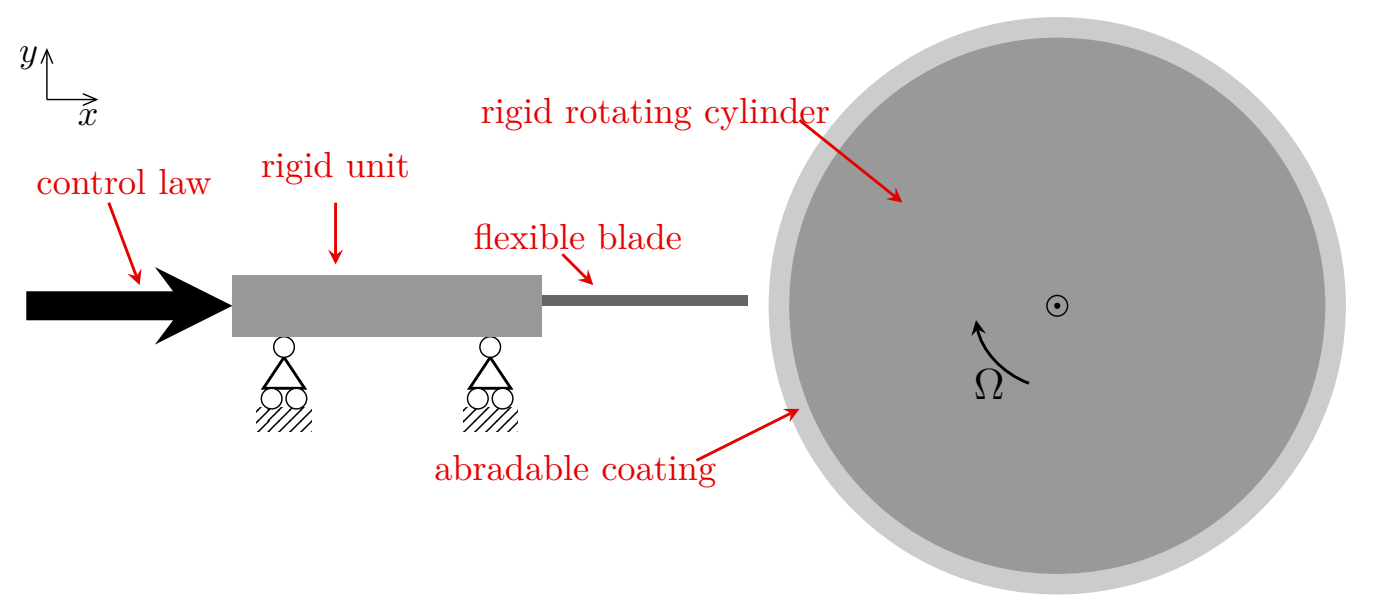

Figure 5. Experimental test rig

cylinder rotates at a fixed angular velocity (a complete rotation is about $50 \mathrm{~ms}$ long), resulting in an interaction velocity of about $20 \mathrm{~m} / \mathrm{s}$. The blade is initially motionless and completely clamped at its root to a rigid unit. Then a force is applied onto the rigid unit, resulting in a displacement along the $x$ axis until about a third of a rotation, where the force is progressively decreased to zero for another third of rotation. As the displacement increases, the blade enters in contact with the rotating cylinder and wears the abradable coating. The incursion of the blade into the coating is not controlled and not measurable from purely geometric considerations since the blade is flexible. The incursion has been estimated to range from zero to about $50 \mu \mathrm{m}$ by [17]. We want to compare the flexural $y$-displacement of the blade measured in the experiment to the one obtained through numerical simulations. The interaction with the cylinder lasts less than one revolution in such a way that there is no interaction with the surface worn during a previous rotation and hence the surface can be considered to be initially smooth at the macro scale.

\subsection{Modeling of the experiment}

The blade is discretized with three-dimensional finite elements and a Craig-Bampton synthesis method is performed. The imposed displacement at the root of the blade is seen as a Dirichlet boundary condition. The blade material parameters are calibrated such that the first eigenfrequencies match those measured experimentally. The blade tip is the potential contact area. The cylinder is seen as rigid and only the abradable coating is meshed as explained in section 3.1. Finally, the abradable material parameters are given in Table 3. These parameters have been chosen based on different sources from the literature $[26,17,5,25]$

\subsection{Results}

The corresponding experimental and numerical flexural displacements are plotted in Fig. 6. The oscillations are caused by contact with the cylinder until about $7 \mathrm{~ms}$. After that, the blade has been pulled back, there is no more contact and only free oscillations of the blade. The number of oscillations during the contact phase is not exactly the same ( 8 in the numerical simulation instead of 9 in the experiment) which can be explained by the uncertainties on the control law driving the blade root. Nevertheless the numerical framework allows for a convincing reproduction of the blade displacement.

The material parameters having being calibrated to match the experiment, they are now used as a reference from which is explored the sensitivity of the blade tip displacement with respect to material 


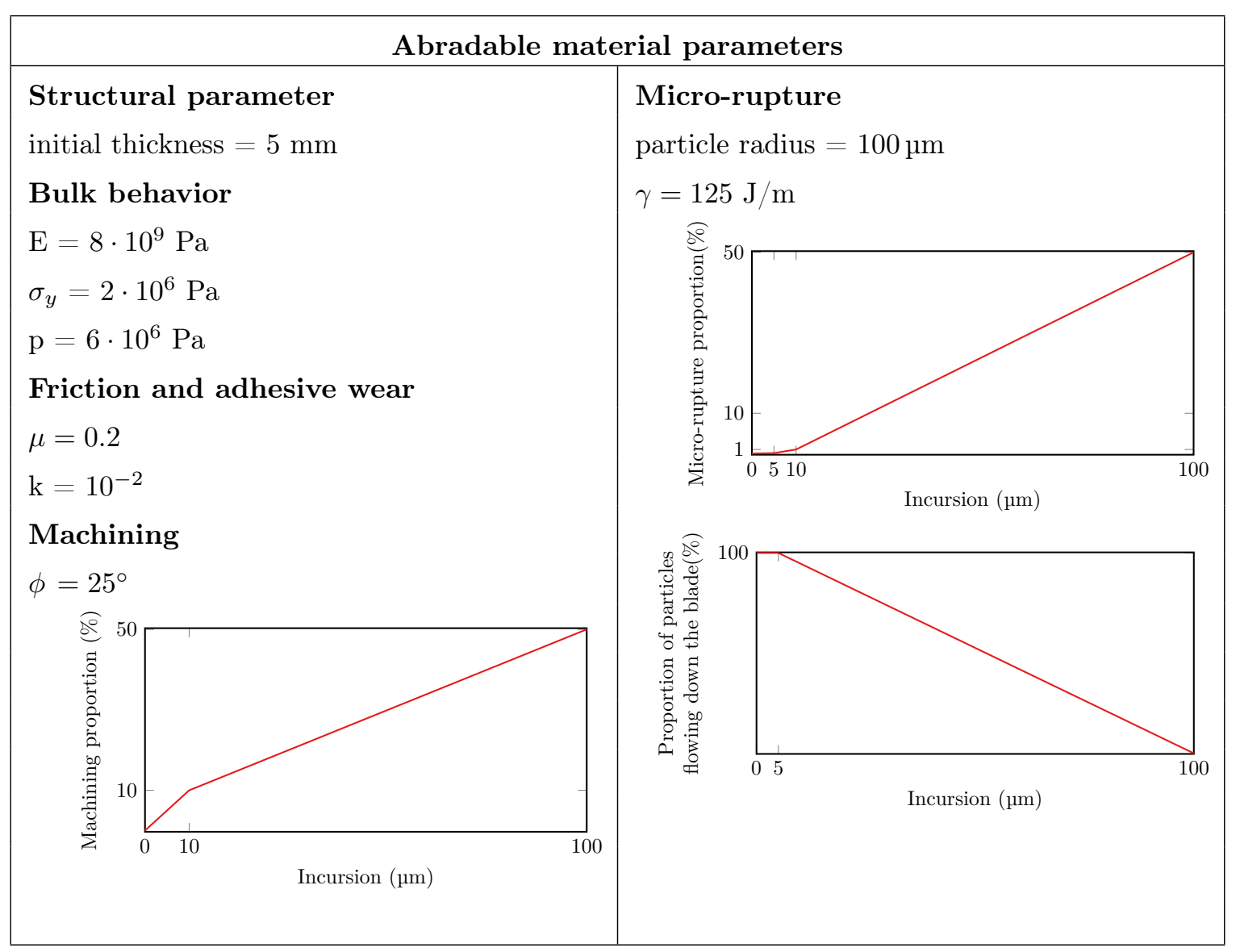

Table 3. Material parameters used for simulation of the experiments

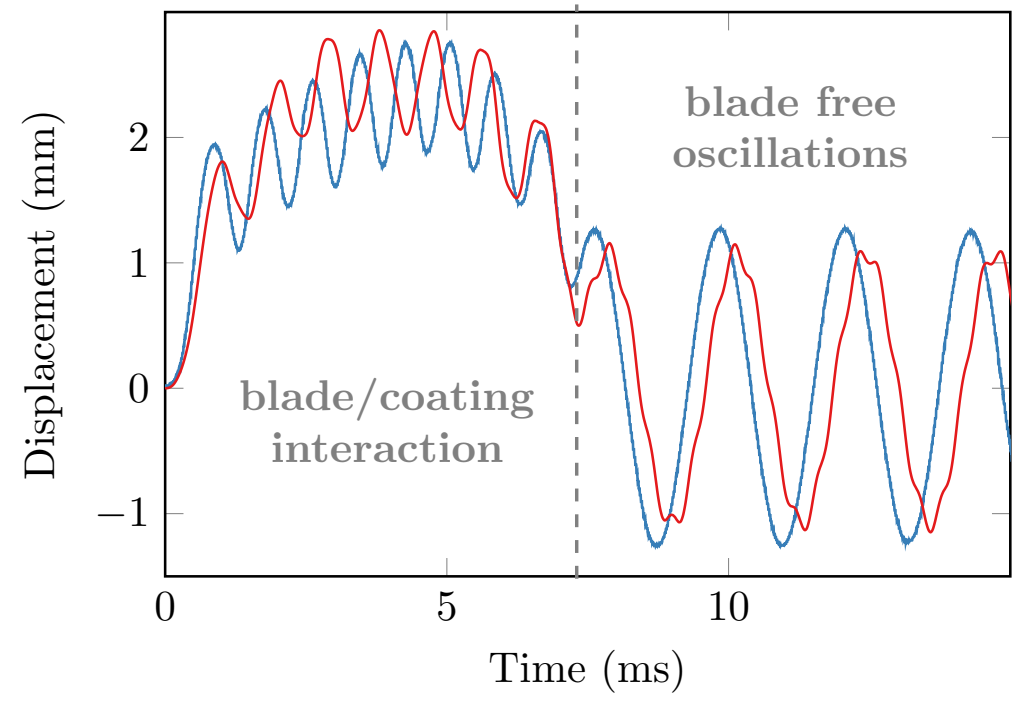

Figure 6. Tangential (flexion) blade tip displacement: experiment [ $[-]$; numerical $[-]$

variations. The goal of this sensitivity analysis is two-fold: first, to ensure that the model is robust, i.e. a small change in parameters does not result in a completely different behavior of the blade; and second, to ensure that the behavior is consistent with the associated wear mechanism.

Parameters listed in Table 3 are used and only one parameter is varied. Corresponding results with the friction coefficient, adhesive wear coefficient, and adhesive wear coefficient are plotted in Figs. 7, 8, and 9 where the second graph represents the amount of abradable coating removed by interaction with the blade along the circumference of the rotating cylinder. Since the interaction takes place only during the rotation of the first half of the circumference of the cylinder, only this first half is plotted. 


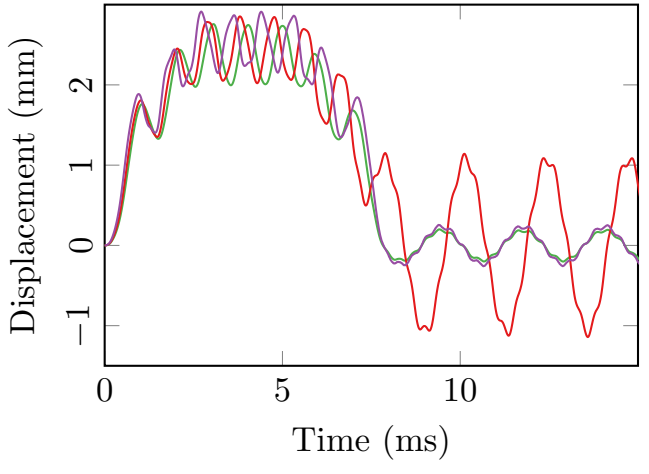

(a) blade tip displacement

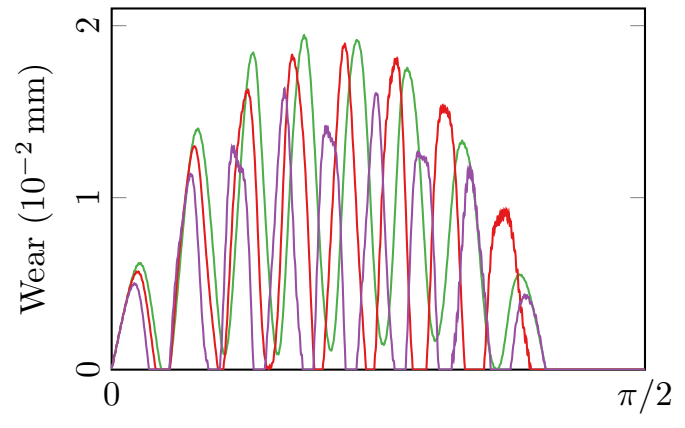

Angular position

(b) coating wear

Figure 7. Sensitivity to friction coefficient: $\mu=0.25[-], \mu=0.3[-]$, and $\mu=0.4[-]$

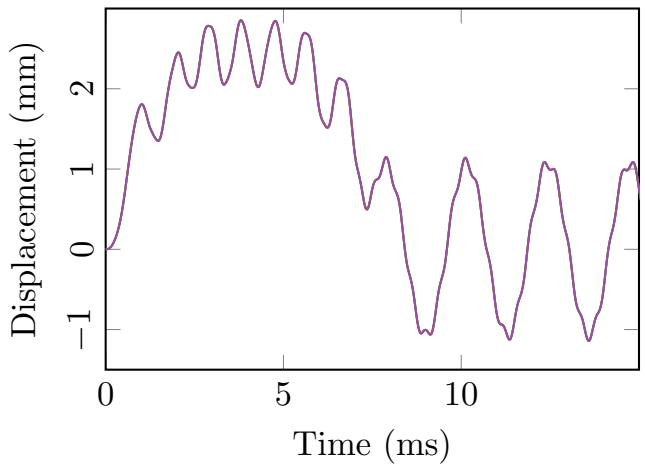

(a) blade tip displacement

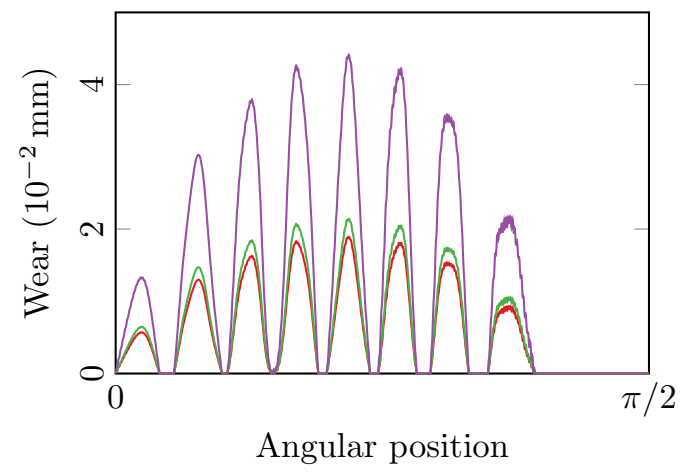

(b) coating wear

Figure 8. Sensitivity to adhesive wear coefficient: $k_{\mathrm{adh}}=10^{-4}[-], k_{\mathrm{adh}}=10^{-2}[-]$, and $k_{\mathrm{adh}}=10^{-1}[-]$

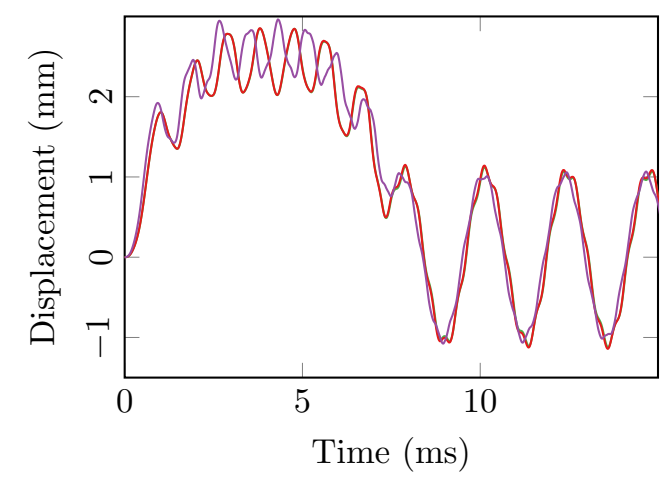

(a) blade tip displacement

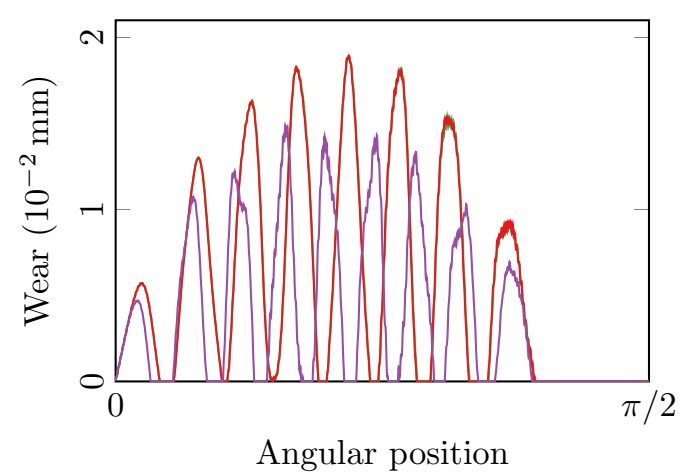

(b) coating wear

Figure 9. Sensitivity to surface energy variation: $\gamma=0[-], \gamma=125[-]$, and $\gamma=12,500[-]$. The green curve is below the red one.

Several observations can be made:

- The friction coefficient does influence the displacement of the blade, and hence the wear of the abradable, but the displacement and wear amplitudes are of the same order of magnitude for distinct coefficients. However, the amplitude of the free oscillations is significantly different for $\mu=0.3$ : this could be explained by the fact that the last contact is in the opposite direction of the motion.

- The adhesive wear coefficient does not influence the blade displacement directly. On the other 
hand, wear of the coating directly depends on it. By Archard's law, the dependence of the adhesive wear on parameter $k_{\text {adh }}$ is linear, all other parameters being equal. This is not clearly seen in Fig. 8b because the overall wear induced by all mechanisms is plotted, not only the wear due to plasticity at junctions. Also notice that if the blade were to interact again with the coating already worn, its displacement would depend on the wear of the coating, and hence, would depend indirectly on the adhesive wear coefficient.

- The influence of the surface energy variation is more intricate: its variation between $\gamma=0$ and $\gamma=125$ has a very limited effect on the dynamics of the blade since the associated curves are almost identical. This could be explained by the fact that below a certain value of the cohesive energy of the abradable, the reaction force onto the blade due to breaking particles is negligible when compared to other reaction forces. On the other hand, at $\gamma=12,500$, the reaction force due to cohesive energy is no longer negligible and the displacement of the associated curve is different. All other parameters of the model can obviously be varied in a similar fashion. There variations also show a good numerical behavior: their influence is noticeable but do not exhibit spurious instability.

\section{Full 3D blade casing interaction}

\subsection{Experiment presentation}

The experimental setup described in [19] involves the last stage of a full-scale aircraft engine low-pressure compressor operating in a vacuumed environment. Contact between the blade and the abradable coating is initiated through centrifugal effects. The frequency of a revolution of the rotor, $f_{\Omega}$, is chosen such that $f_{\Omega} \approx f_{1 \mathrm{~F}} / 6$, where $f_{1 \mathrm{~F}}$ is the first eigenfrequency of the blade. The interaction is solely activated by a slightly longer blade. The blade tip exhibits a high amplitude response, and the coating is worn out at six equally spaced locations along the casing circumference, called wear lobes as depicted in Fig. 10 .

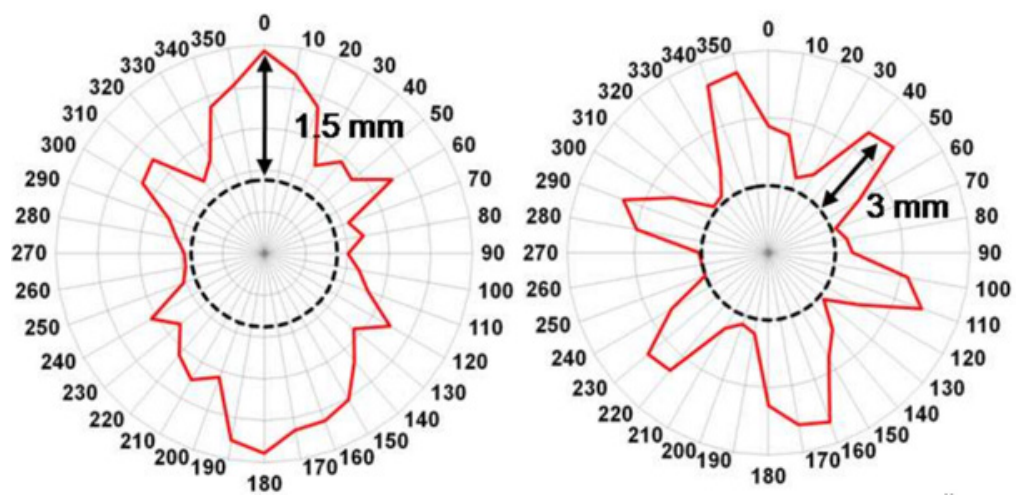

Figure 10. Final abradable wear profile at the leading (left) and trailing (right) edges of the longer blade for the experiment described in [19]

\subsection{Numerical reproduction of the experiment}

The parameters used for the numerical experiment are the following:

- The blade geometry used for the finite element mesh comes from the CAD of the blade.

- The angular velocity is constant, its value is the same as in the final plateau velocity of the experiment.

- The simulation is carried out for 200 revolutions of the blade: this is much shorter than in the actual experiment but is assumed to be representative of an extended interaction.

- The initial clearance between the blade and the casing is $1 \mathrm{~mm}$. The casing is progressively ovalized so that the abradable liner comes into contact with the blade. The maximum nominal penetration of the blade into the coating, should the blade not deform, is fixed to $1 \mathrm{~mm}$.

- The abradable material parameters are the ones of the test rig simulation introduced in the previous section. 
The simulation approximately reproduces the experiment. As shown in Fig. 11, the wear patterns are similar: two wear lobes at the leading edge and six lobes at the trailing edge. The spectrogram in Fig. 12 also shows complex behavior: the blade first responds mainly on the first bending mode, then the second bending mode becomes dominant around revolution 14 and for the remainder of the simulation.
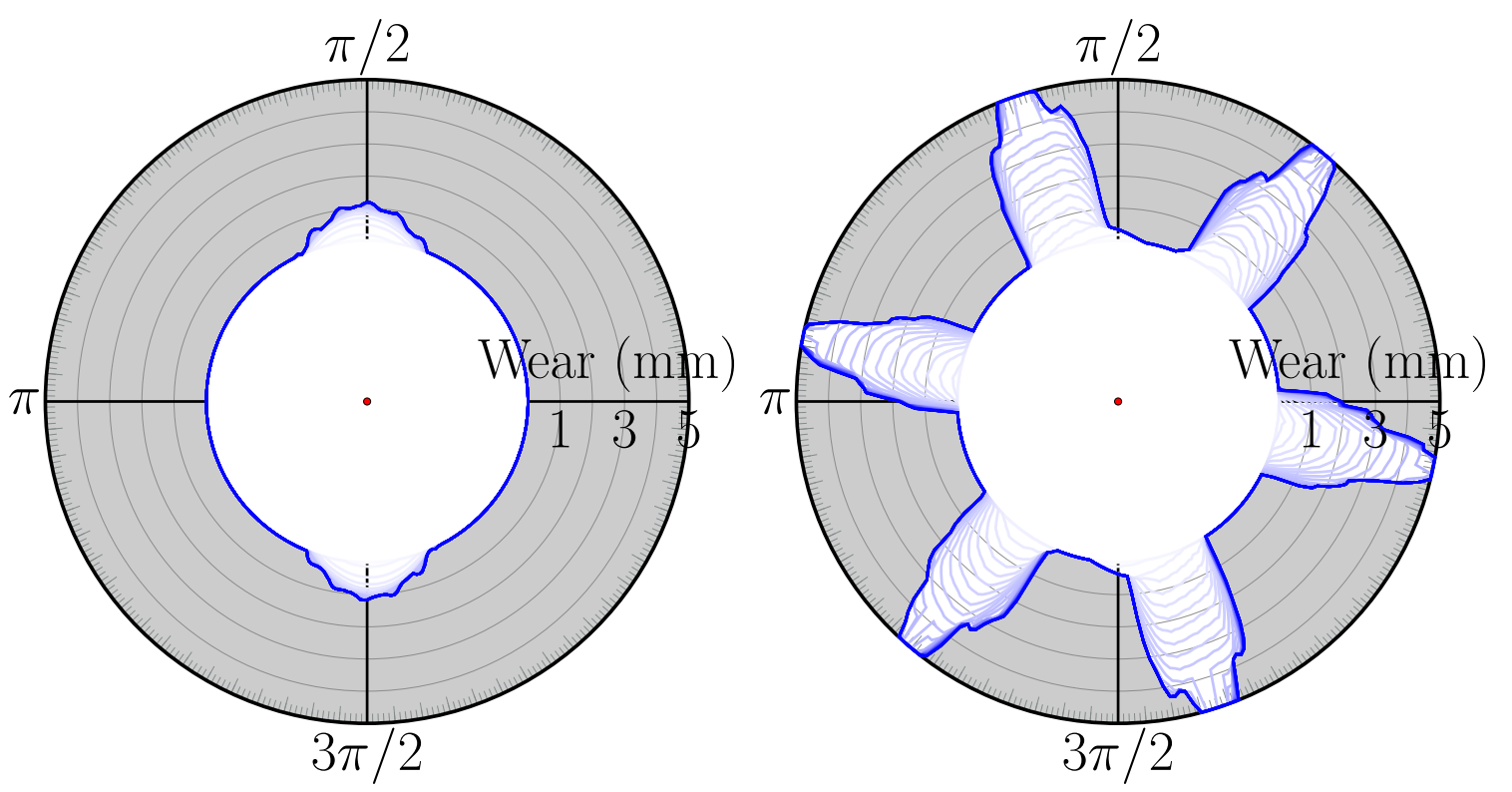

Figure 11. Final wear of the casing (magnified) at the leading (left) and trailing (right) edges on the numerical simulation

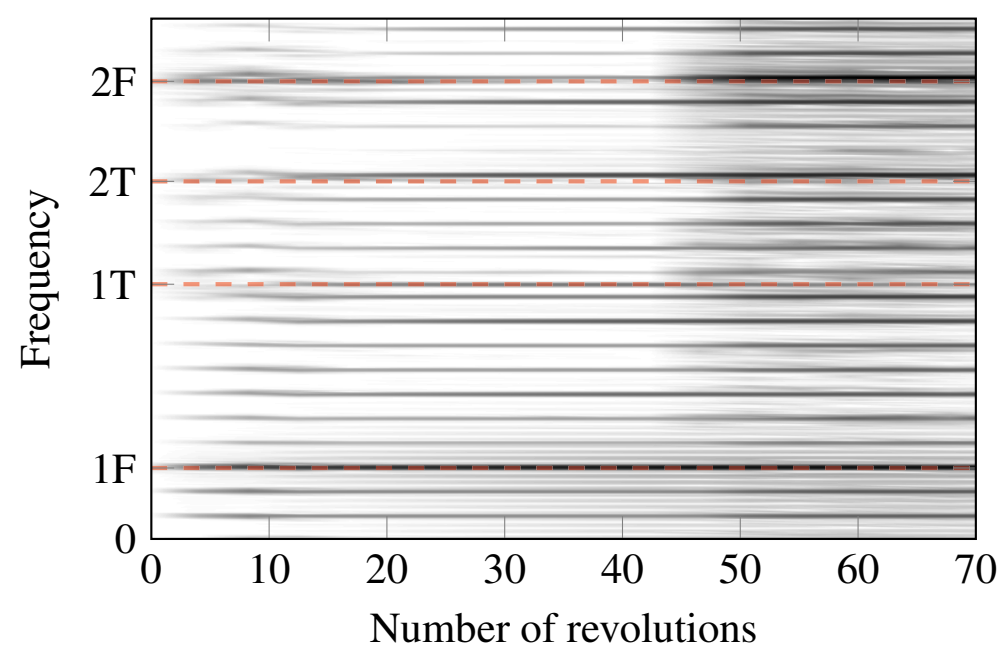

Figure 12. Spectrogram of the leading edge displacement (only the beginning is shown, the spectrogram is almost time-independent during the rest of the simulation). Dashed lines represent eigenfrequencies of the blade.

\subsection{Wear maps}

Focus is now made on the wear of the abradable coating. A nice way to analyze the variation of wear depending on configuration parameters is by the mean of wear maps. A wear map is a color plot where wear of the abradable coating at the end of an interaction is displayed for a range of angular velocities. For each angular velocity, meaning for one column of the map, a color code indicates the quantity of abradable removal along the casing circumference: from white if the coating is intact to black where 
maximum wear is observed [2]. For all the plotted wear maps, wear is always measured at the trailing edge, where most sophisticated patterns are observed.

A wear map with the parameters of the previous simulation is plotted in Fig. 13: all simulations displayed have the same configuration except for the varying angular velocity. The map shows that the wear patterns are highly dependent on the angular velocity. For most of the velocities, the blade response to an interaction with the casing is of low amplitude and the coating is only moderately worn out with a two-lobe pattern, corresponding to the casing ovalization. Nevertheless, for many velocities, the eigenfrequency of the blade is near an engine order, the blade response is high, and hence the wear on the casing is important, with the number of wear lobes being equal to the engine order.
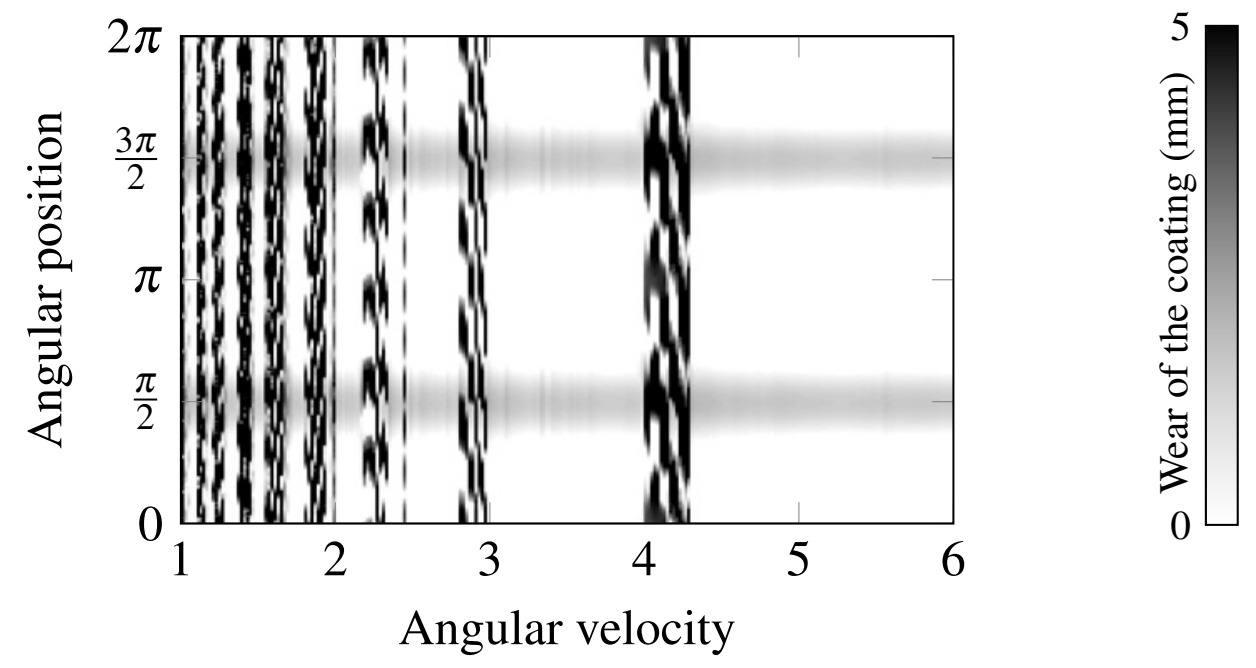

Figure 13. Numerically predicted wear map

\subsection{Effect of wear law parameters on the coating wear}

Our goal is to understand how the abradable material properties affect the wear of the coating, in order to control and possibly reduce it. The choice of a material is the result of a compromise between several requirements upon the abradable material. Nevertheless, attention is here paid to the wear behavior only. In this section, the same configuration as the previous one is used except that the material parameters are varied. Five examples of variations are presented.

\subsubsection{Adhesive wear}

Only the adhesive wear law is activated. The results for a variation of the Archard wear coefficient are presented in Fig. 14(a). As expected, a higher coefficient is correlated to a higher final wear. It should be noted however that the dynamics of the blade is complex: less wear at the beginning can result in a greater incursion for the next revolutions, hence more energy transferred to the blade, more displacement of the blade edge, hence more contacts with the coating and finally more wear at the end of the simulation. For instance, $k_{\text {adh }}=10^{-4}$ seems to induce more wear of the abradable than $k_{\text {adh }}=10^{-3}$ does.

\subsubsection{Machining wear}

The machining wear law only is activated and results are presented in Fig. 14(b) for the variation of the angle between the shear plane and the coating normal direction. Clearly, a higher the angle leads to less wear. This is consistent with the fact that the force associated to machining wear decreases when the angle increases. The impact of this parameter on wear is minor overall.

\subsubsection{Micro-rupture wear}

The micro-rupture wear law is activated. Variations of three parameters associated to this law are presented. 

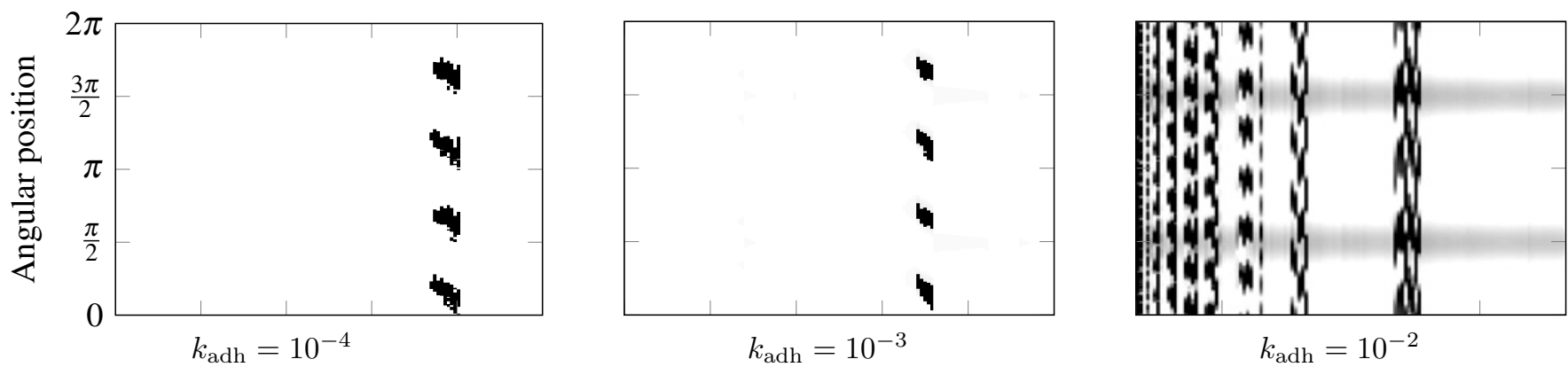

(a) Adhesive wear: sensitivity to Archard coefficient
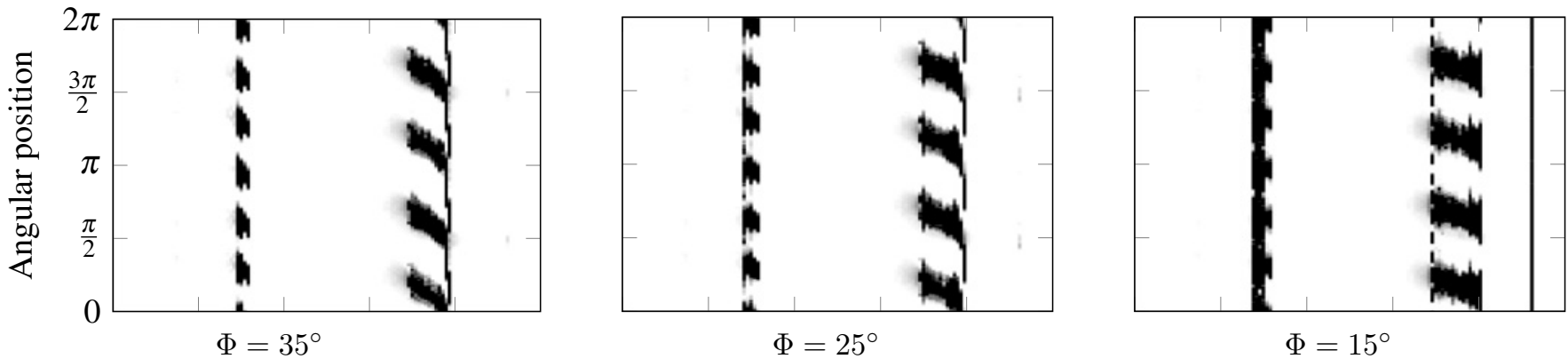

(b) Machining wear: sensitivity to shear plane angle
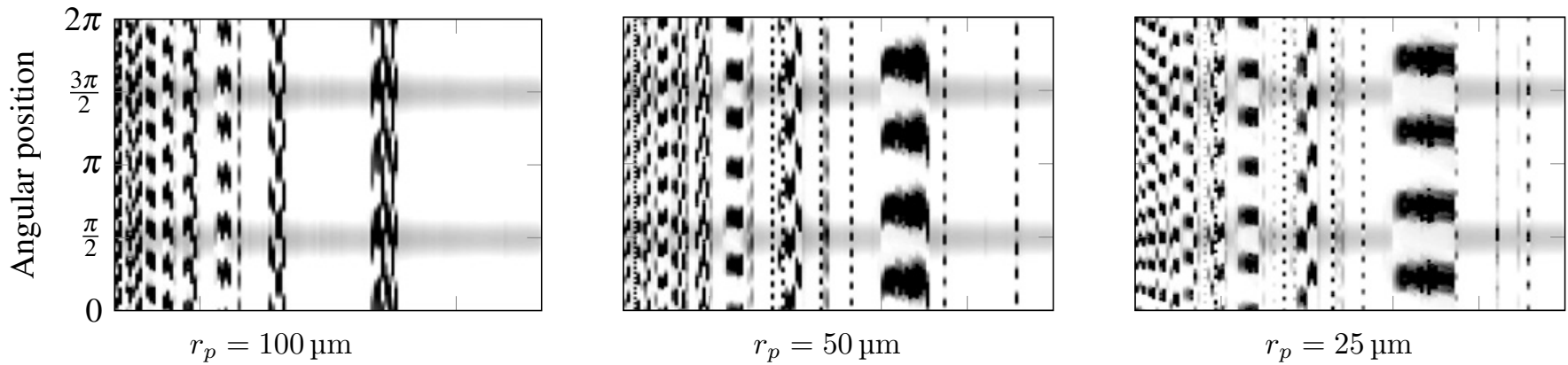

(c) Micro-rupture wear: sensitivity to particle size
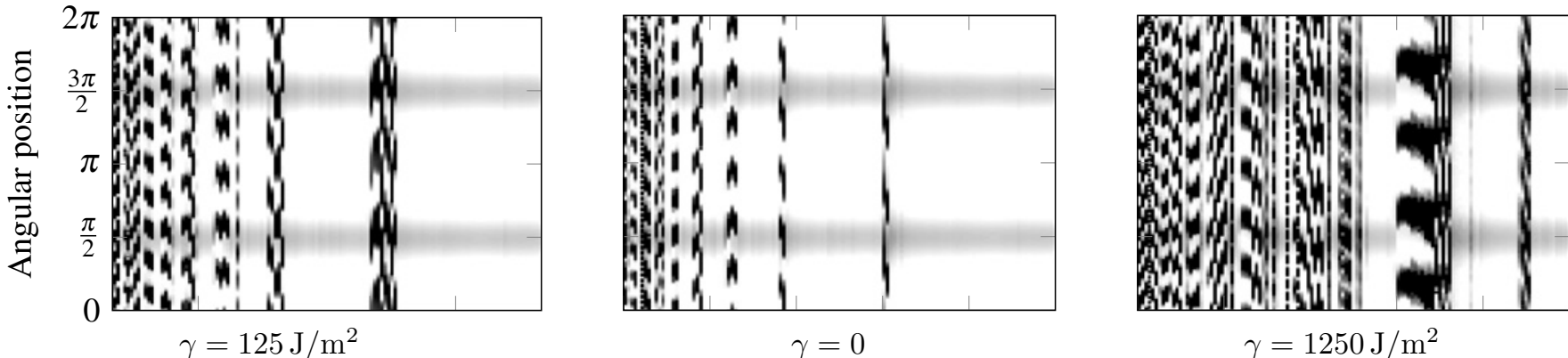

(d) Micro-rupture wear: sensitivity to cohesive energy
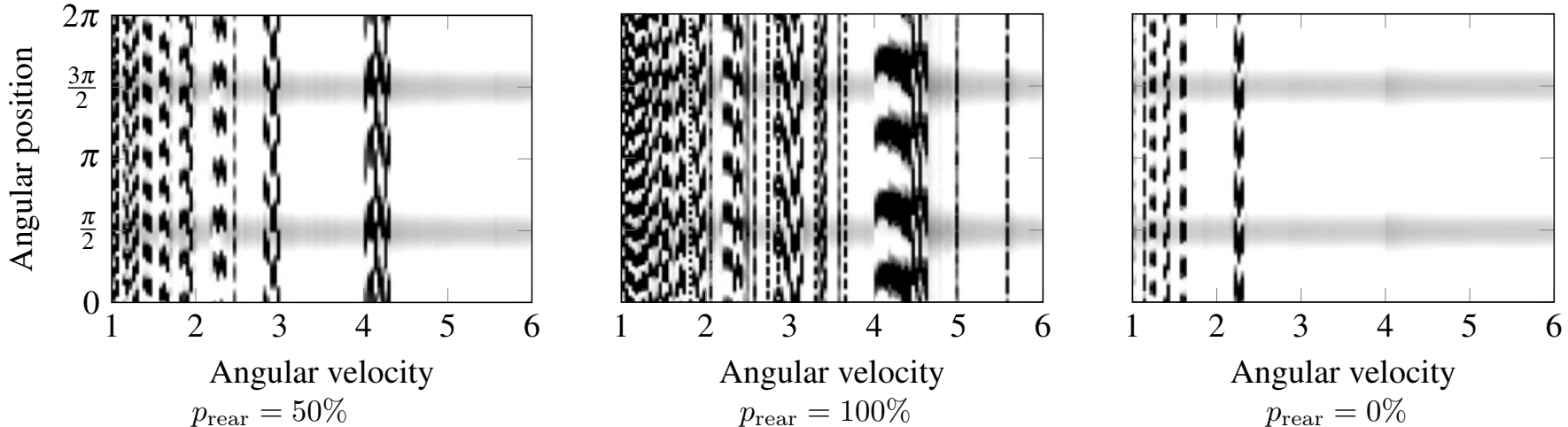

(e) Micro-rupture wear: sensitivity to ejected proportion at blade rear

Figure 14. Wear maps for various wear laws. Same color scale as Fig. 13 
Particle size The impact of particle size on the wear of the coating is two-fold, with opposite effects:

- since the ejected particle size is bigger, all things being equal, the instantaneous wear will be bigger;

- at the same time, if the particle is big, the wear is important at the beginning, and the blade will seldom contact the casing, resulting in less vibration energy being transferred, and hence no resonance of the blade, and no further wear as a consequence.

The wear maps, see Fig. 14(c), show that in this specific case, the second effect is dominant, since wear is more important when the particles are smaller. This result is interesting because it suggests that a coarsening of the micro-structure of the abradable material can lead, perhaps counter-intuitively, to less wear if the micro-rupture wear mechanism is dominant.

Cohesive energy The more energy needed to break particles, the more reacting force exerted on the blade, the more vibration energy transferred to the blade and hence more wear is to be expected. This is coherent with the wear maps of Fig. 14(d).

Particles ejected at the rear of the blade If the micro-rupture particles are ejected at the front of the blade, they are not compressed towards the casing by the tip of the blade, hence the normal reaction force exerted on the blade is smaller. Conversely, if they are only ejected at the rear, then they have been compressed under the blade tip, and thus the normal reaction force increases. This corroborates the wear maps in Fig. 14(e): when particles are ejected to the rear, the wear of the coating is more important.

\subsubsection{Global remarks on parameter variations}

Different wear laws and parameters, that is to say, different material properties, result in different levels of coating wear. One can however notice the global similarities between wear maps: the wear patterns, especially the number of lobes and the angular velocities for which the patterns emerge are very similar from one material to the other. As an example, consider that the 6 -lobe pattern around $\Omega=2.2$ and the 4-lobe pattern between $\Omega=4$ and $\Omega=5$ appear for virtually all material parameters.

\section{Conclusion}

A new framework targeting the simulation of coating wear in turbo-machinery has been presented. The model is based on the phenomenology of wear of abradable coatings reported in the literature. Four independent wear mechanisms are derived, and each one of them is associated to a simple macro model. The global model is then tested within a explicit numerical scheme accounting for the full 3D geometry of the blade. Two studies on the reproduction of a test rig experiment and a full scale experiment are then presented. For this latter configuration, a parametric study on the abradable material wear properties is conducted. Results show how the introduced material parameters affect the coating wear and two opposite trends are observed. On the one hand, the energy of vibration transferred to the blade during contact will trigger its displacement, and as a consequence, tend to activate new contact occurrences. On the other hand, contact events induce wear mechanisms, which increase the operating clearance between the blade and the coating, and thus mitigate further contacts to ultimately decrease the transferred energy of vibration. These contradictory yet interrelated phenomena are typically nonlinear and illustrate the complexity of the blade dynamics.

It is believed that this model is sufficiently reliable to properly capture the blade dynamics during a contact occurrence with the stator. It also provides a convenient tool to understand the impact of abradable behavior on the blade dynamics, so that it gives useful information in order to reduce the wear of the casing. Finally, it should be mentioned that this model can be augmented with thermal effects through a state variable taking into account temperature which the parameters presented on this study (such as the friction coefficient) may depend on.

\section{Acknowledgments}

Thanks go to Safran Snecma for its technical and financial support. 


\section{References}

[1] Sarah Baïz, Jacky Fabis, Xavier Boidin, and Yannick Desplanques. Experimental investigation of the blade/seal interaction. Proceedings of the Institution of Mechanical Engineers, Part J: Journal of Engineering Tribology, 227(9):980-995, 2013. [hal-00863616].

[2] Alain Batailly, Mathias Legrand, Antoine Millecamps, and François Garcin. Numerical-experimental comparison in the simulation of rotor/stator interaction through blade-tip/abradable coating contact. Journal of Engineering for Gas Turbines and Power, 134(8), 2012. [hal-00746632].

[3] M.O. Borel, A.R. Nicoll, H.W. Schläpfer, and R.K. Schmid. The wear mechanisms occurring in abradable seals of gas turbines. Surface and Coatings Technology, 39-40(0):117-126, 1989. [hal-01553649].

[4] Roy Craig and Mervyn Bampton. Coupling of substructures for dynamics analyses. AIAA Journal, 6(7):1313-1319, 1968. [hal-01537654].

[5] Marion Cuny, Sylvain Philippon, Pierre Chevrier, and François Garcin. Experimental measurement of dynamic forces generated during short-duration contacts: application to blade-casing interactions in aircraft engines. Experimental Mechanics, 54(2):101-114, 2014. [hal-01430522].

[6] Azzedine Dadouche, Martin Conlon, Waldemar Dmochowski, Brian Liko, and Jean-Pierre Bédard. Experimental evaluation of abradable seal performance at high temperature. In ASME Turbo Expo 2008: Power for Land, Sea, and Air, pages 143-150. American Society of Mechanical Engineers, 2008. [hal-01430519].

[7] Corentin Delebarre, Vincent Wagner, Jean-Yves Paris, Gilles Dessein, Jean Denape, and Julien Gurt-Santanach. An experimental study of the high speed interaction between a labyrinth seal and an abradable coating in a turbo-engine application. Wear, 316(1):109-118, 2014. [hal-01060023].

[8] Houda-Imène Faraoun, Jean-Louis Seichepine, Christian Coddet, Hafid Aourag, Jochen Zwick, Noël Hopkins, Dieter Sporer, and Manuel Hertter. Modelling route for abradable coatings. Surface and Coatings Technology, 200(22):6578-6582, 2006. [hal-01430527].

[9] Mikell Groover. Fundamentals of modern manufacturing: materials processes, and systems. John Wiley \& Sons, New York, 2007.

[10] Georges Jacquet-Richardet, Mohamed Torkhani, Patrice Cartraud, Fabrice Thouverez, Thouraya Nouri Baranger, Mathieu Herran, Claude Gibert, Sébastien Baguet, Patricio Almeida, and Loic Peletan. Rotor to stator contacts in turbomachines. Review and application. Mechanical Systems and Signal Processing, 40:401-420, 2013. [hal-00934050].

[11] Richard Johnston. The sensitivity of abradable coating residual stresses to varying material properties. Journal of Thermal Spray Technology, 18(5-6):1004-1013, 2009. [hal-01430524].

[12] Mathias Legrand and Christophe Pierre. Numerical investigation of abradable coating wear through plastic constitutive law: application to aircraft engines. In ASME 2009 International Design Engineering Technical Conferences and Computers and Information in Engineering Conference, pages 907-916. ASME, 2009. [hal-00413728].

[13] Mathias Legrand, Alain Batailly, and Christophe Pierre. Numerical investigation of abradable coating removal in aircraft engines through plastic constitutive law. Journal of Computational and Nonlinear Dynamics, 7(1), 2011. [hal-00627526].

[14] Hui Ma, Xingyu Tai, Qingkai Han, Zhiyuan Wu, Di Wang, and Bangchun Wen. A revised model for rubbing between rotating blade and elastic casing. Journal of Sound and Vibration, 337:301-320, 2015. [hal-01430515].

[15] Xiao Ma and Allan Matthews. Investigation of abradable seal coating performance using scratch testing. Surface and Coatings Technology, 202(4):1214-1220, 2007. [hal-01430526]. 
[16] Xiao Ma and Allan Matthews. Evaluation of abradable seal coating mechanical properties. Wear, 267:1501-1510, 2009. [hal-01430513].

[17] Romain Mandard, Jean-François Witz, Xavier Boidin, Jacky Fabis, Yannick Desplanques, and Jean Meriaux. Interacting force estimation during blade/seal rubs. Tribology International, 82: 504-513, 2015. [hal-01081384].

[18] William Marscher. A phenomenological model of abradable wear in high performance turbomachinery. Wear, 59(1):191-211, 1980. [hal-01555289].

[19] Antoine Millecamps, Jean-François Brunel, Philippe Dufrénoy, François Garcin, and Marco Nucci. Influence of thermal effects during blade-casing contact experiments. In ASME 2009 International Design Engineering Technical Conferences and Computers and Information in Engineering Conference, pages 855-862, 2009. [hal-01223060].

[20] Antoine Millecamps, Alain Batailly, Mathias Legrand, and François Garçin. Snecma's viewpoint on the numerical and experimental simulation of blade-tip/casing unilateral contacts. In $A S M E$ Conference Proceedings: Turbo Expo 2015, 2015. [hal-01223582].

[21] Edward Novinski, John Harrington, and John Klein. Modified zirconia abradable seal coating for high temperature gas turbine applications. Thin Solid Films, 95(3):255-263, 1982. [hal-01553705].

[22] Corso Padova, Jeffrey Barton, Michael Dunn, Steve Manwaring, Gamaliel Young, Maurice Adams, and Michael Adams. Development of an experimental capability to produce controlled blade tip/ shroud rubs at engine speed. Journal of turbomachinery, 127(4):726-735, 2005. [hal-01553829].

[23] François Peyraut, Jean-Louis Seichepine, Christian Coddet, and Manuel Hertter. Finite element modeling of abradable materials - Identification of plastic parameters and issues on minimum hardness against coating's thickness. International Journal for Simulation and Multidisciplinary Design Optimization, 2(3):209-215, 2008. [hal-01555280].

[24] Ernest Rabinowicz. Friction and wear of materials. Wiley, New York, 1995.

[25] Arnaud Ribesse, Audrey Favache, Guerric Lemoine, Christian Bailly, Pascal Jacques, and Thomas Pardoen. Multiscale mechanical and tribological characterization of alsi abradable material. In 7th International Conference on Fracture of Polymers, Composites and Adhesives, Les Diablerets, Switzerland, 2014.

[26] Richard Karl Schmid. New high temperature abradables for gas turbines. PhD thesis, Eidgenössische Technische Hochschule Zürich, 1997.

[27] Sunil Sinha. Rotordynamic analysis of asymmetric turbofan rotor due to fan blade-loss event with contact-impact rub loads. Journal of Sound and Vibration, 332(9):2253-2283, 2013. [hal-01555281].

[28] Julien Vincent. Étude expérimentale des interactions aube-abradable à très grandes vitesses : influence du matériau et de sa microstructure. PhD thesis, Université de Lorraine, 2015.

[29] Robin Williams. Simulation of blade casing interaction phenomena in gas turbines resulting from heavy tip rubs using an implicit time marching method. In ASME Conference Proceedings: Turbo Expo 2011, pages 1007-1016, 2011. [hal-01555287].

[30] Thomas Wilson Wright. The physics and mathematics of adiabatic shear bands. Cambridge University Press, Cambridge, 2002.

[31] Maozhong Yi, Jiawen He, Baiyun Huang, and Huijiu Zhou. Friction and wear behaviour and abradability of abradable seal coating. Wear, 231(1):47-53, 1999. [hal-01555292].

[32] Maozhong Yi, Huang Baiyun, and He Jiawen. Erosion wear behaviour and model of abradable seal coating. Wear, 252(1):9-15, 2002. [hal-01555293]. 